\title{
Foveal macular pigment dip in offspring of age-related macular degeneration patients is inversely associated with omega-3 index
}

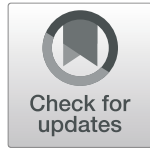

\author{
Grant A. Rutledge ${ }^{1,2,3^{*}}$ D , Steven G. Pratt ${ }^{1}$, Stuart P. Richer ${ }^{4}$, Byki Huntjens ${ }^{5}$, C. Blake Perry ${ }^{1}$, Gunilla Pratt ${ }^{1}$ and
} Carla Podella ${ }^{4}$

\begin{abstract}
Background: Offspring of parent(s) with age-related macular degeneration (AMD) have a 45\% lifetime risk of developing the disease. High foveal macular pigment optical density (MPOD) is protective, whereas individuals with a "foveal macular pigment dip" (FMPD) are at increased risk. Shortage of the dietary carotenoids lutein, zeaxanthin as well as fish consumption are reported AMD risk factors. This Early Biomarkers of AMD (EBAMD) study evaluates serum factors that protect foveal MPOD architecture in Caucasian offspring of parent(s) with AMD.

Methods: $N=130$ subjects [mean (SD) age 62.8 (8.6) years; 36/94 male/female] were recruited from Scripps Health/ Scripps Memorial Hospital/ Scripps Mericos Eye Institute between 2012 and 2017. Macula pigment 3D topography was evaluated using specular reflectance. Buccal genetic cheek swab, circulating serum dietary carotenoids and long-term RBC omega-3 fatty acid status, as well as common secondary clinical structural and vision function parameters were obtained.

Results: $41 \%$ of offspring of AMD parent(s) presented with FMPD. These offspring were about 4 years younger than those without FMPD (controls; $P=0.012$ ) and had thinner foveas $(P=0.010)$. There were no differences in gender, BMI, \% body fat, visual acuity or contrast sensitivity between those with and without FMPD. \% RBC membrane docosahexaenoic acid (DHA) was reduced in FMPD offspring vs. control offspring $(P=0.04)$. The Omega3 Index was significantly decreased in the FMPD group $(P=0.03)$.

Conclusions: The percentage of FMPD in AMD offspring is nearly twice that reported for the general population in the scientific literature. Offspring presenting FMPD had similar AMD genetic risk, but significantly reduced \% RBC membrane omega-3 fatty acids and thinner foveas compared with those without FMPD. Our data supports the importance of 'essential fatty' acids as an independent AMD risk factor.
\end{abstract}

Keywords: Macular pigment (MP), Macular pigment optical density (MPOD), Foveal macular pigment dip (FMPD), Lutein, Zeaxanthin, Eicosapentaenoic acid (EPA), Docosahexaenoic acid (DHA), Omega-3 index

\footnotetext{
* Correspondence: Grant.Rutledge@Tufts.edu

'Scripps Health/Scripps Memorial Hospital/Scripps Mericos Eye Institute -

Scripps Clinical Research Service, La Jolla, CA, USA

${ }^{2}$ Department of Ecology and Evolutionary Biology, University of California, Irvine, CA, USA

Full list of author information is available at the end of the article
}

(c) The Author(s). 2020 Open Access This article is licensed under a Creative Commons Attribution 4.0 International License, which permits use, sharing, adaptation, distribution and reproduction in any medium or format, as long as you give appropriate credit to the original author(s) and the source, provide a link to the Creative Commons licence, and indicate if changes were made. The images or other third party material in this article are included in the article's Creative Commons licence, unless indicated otherwise in a credit line to the material. If material is not included in the article's Creative Commons licence and your intended use is not permitted by statutory regulation or exceeds the permitted use, you will need to obtain permission directly from the copyright holder. To view a copy of this licence, visit http://creativecommons.org/licenses/by/4.0/. The Creative Commons Public Domain Dedication waiver (http://creativecommons.org/publicdomain/zero/1.0/) applies to the data made available in this article, unless otherwise stated in a credit line to the data. 


\section{Background}

Age related macular degeneration (AMD) causes progressive loss of vision in older adults [1] and is responsible for significant visual impairment in the United States [2]. Genetic studies show hereditary susceptibility to developing AMD [3-5], whereby monozygotic twin studies have identified an increased risk for developing AMD in individuals whose identical twin has AMD even when environmental factors are not shared [6]. Other studies support this shared genetic predisposition for AMD among siblings and twins [7, 8].

Human macular pigment consists of the two dietary xanthophyll carotenoids, lutein and zeaxanthin, as well as lutein's metabolite meso-zeaxanthin $[9,10]$. Reduced central macular pigment optical density (MPOD) is often associated with major AMD risks including increased age, family history, smoking [11], female gender [12], light iris color [13], and inflammatory conditions such as diabetes [14]. Healthy appearing retinas without AMD but predisposed to the disease due to advance AMD in the fellow eye, presented significantly less MPOD than aged-matched controls [10]. Although MPOD was not measured in the Age-related Eye Disease Study II (AREDS II), repletion of lutein and zeaxanthin in high risk AMD patients was associated with a $26 \%$ AMD risk reduction in the low dietary carotenoid intake group, suggesting a causal role within a recent review of macular pigment [15]. In addition, macular pigment architecture most commonly declines exponentially from the foveolar [16-18]. Atypical MPOD spatial profiles have been observed in approximately $20 \%$ of subjects containing a secondary pigment peak/ring [19-22] or central dip [23-25] here collectively termed the "foveal macular pigment dip" (FMPD). Increased prevalence of atypical central dip profiles is a further risk factor for AMD, and has been associated with age [24], smoking [24], certain ethnicities [25], and intake of dietary carotenoids [26].

AMD risk variants in the complement system point to the important role of the immune response and inflammation in the pathogenesis of AMD [27]. An established dietary risk factor for the development of AMD is omega-3 fatty acid intake, with emerging emphasis upon the docosahexaenoic (DHA) fraction [28-30]. A systematic literature review determined that dietary omega-3 fatty acids are associated with lower risk for developing AMD [31]. It is thought that higher fish intake is associated with lower risk for developing AMD, in part because of its high concentrations of DHA [32]. Furthermore, DHA accounts for approximately $50 \%$ of the polyunsaturated fatty acids (PUFAs) of cell membranes in the central nervous system with the highest concentrations within photoreceptor outer segments and synapses [33].
The primary aim of the early biomarkers of AMD study (EBAMD) is to investigate the prevalence of FMPD amongst healthy but high-risk AMD offspring. Secondly, EBAMD evaluates its association with genetic risk, carotenoid and omega-3 fatty acid status, and other subclinical biomarkers.

\section{Methods}

\section{Recruitment}

Informed consent following the tenets of the Declaration of Helsinki were obtained from a staggered recruitment registry of $n=140$ non-smoking offspring of AMD parent(s) in the well-educated, well nourished, active and affluent Caucasian population of La Jolla, CA. The 5year study commenced on 01/01/2012 following Scripps Health IRB approval (11-5677). Subjects were recruited from Scripps Health/ Scripps Memorial Hospital/ Scripps Mericos Eye Institute. Individuals interested in participating in the study were asked to participate in a free screening visit/eye exam conducted by the study physician (SGP). Subjects meeting all inclusion criteria after the screening visit were asked to participate in the study and scheduled for their study visit.

\section{Inclusion criteria}

1) Age $>40$ years; 2) no history of cigarette smoking; 3 ) No visible AMD pathology defined by AREDS [34] or confounding ocular/ systemic disease; 4) Mother and/or father with AMD diagnosed by an ophthalmologist. 5) Patients were free of other ocular and systemic diseases that could affect MPOD, ocular structure and visual function as determined by an ophthalmologist (SGP).

\section{MPOD and dermal carotenoids}

Objective 3D Specular reflectance MPOD topography of peak and integrated volume were determined by the method of specular reflectance using an ARIS (Automated Retinal Imaging System, Visual Pathways, Inc., Prescott, AZ) [35]. The measurement involves capturing a specular reflectance single wavelength $500 \mathrm{~nm}$ image, through a dilated pupil at 2 retinal locations: the fovea having maximum MPOD and a peripheral retinal location where MPOD is minimal. Peak subjective heterochromic flicker photometric 1-degree MPOD using QuantifEye $^{\circ}$ (ZeaVision, Chesterfield, MO) was also acquired.

The ARIS Macurate ${ }^{\mathrm{Tu}}$ Macular Pigment software module displays the 7-degree color coded 3D in vivo representation of MPOD architecture, quantifying the 1degree peak, 2-degree peak and volume of retinal foveal carotenoid pigmentation using single wavelength autoreflectance [36-38] (Fig. 1). Unidentifiable images were removed from the data set, $n=10(\mathrm{BH})$. We defined the MPOD spatial profile as a central dip if visually present 


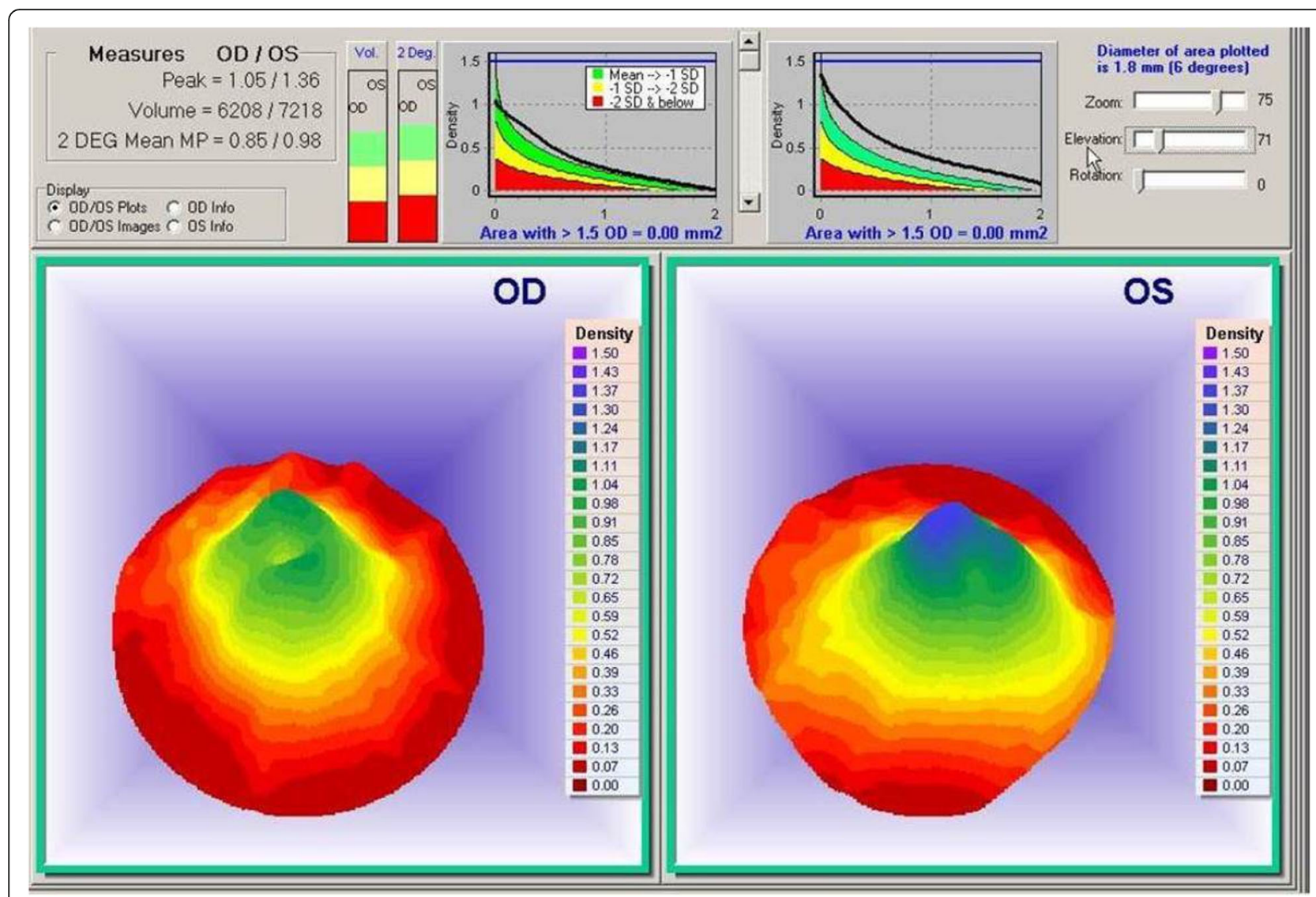

Fig. 1 Baseline ARIS specular reflectance images showing the macula pigment foveal dip phenomenon in subject \#22, female, age 61. The OD image shows a foveal macular pigment dip (FMPD) while OS shows a normal macula pigment distribution

and at least one coefficient of repeatability (CoR; i.e., the average within-subject SD) below the MPOD measurement at 2 degrees). The CoR of the ARIS was found to be 0.17 density units $(\mathrm{du})$ following repeated MPOD measurements in 11 volunteers.

Peak subjective heterochromic flicker photometric MPOD at 1 degree was also determined using the QuantifEye $^{\circ}$ (ZeaVision, Chesterfield, MO) instrument. Palm skin carotenoids, a measure of systemic carotenoid intake, was determined using the resonant Raman spectroscopic BioPhotonic ${ }^{\bullet}$ Scanner (Pharmanex, Inc., Provo, UT) [39].

\section{Foveal retinal thickness, visual acuity and contrast sensitivity}

Spectral domain optical coherence tomography (SDOCT) scans, for foveal retinal thickness (cRT) through dilated pupils, was accomplished with the Topcon Spectral Domain 100 (Oakland, NJ) in a subset $(n=72)$ of offspring. Snellen visual acuity through best spectacle correction was recorded and converted to decimal format. Photopic contrast sensitivity at 5 spatial frequencies was evaluated using a Stereo Optical Functional Vision
Analyzer (Stereo Optical, Chicago, IL, USA) and the Area Under Curve (AUC) calculated as described in our previous studies $[36,40]$.

\section{Serum carotenoids, RBC omega- 3 fatty acids and Spectracell ${ }^{\oplus}$}

Serum carotenoids (lutein and zeaxanthin) from 126 participants were determined by Pennington Biomedical Research Center (www.pbrc.edu). Volunteers were grouped according to low $(<2.9 \mu \mathrm{g} / \mathrm{dL})$ or high serum $\mathrm{Z}(\geq 2.9 \mu \mathrm{g} /$ $\mathrm{dL}$ ) since the HPLC column used to measure $\mathrm{Z}$ was not sensitive to values lower than $2.9 \mu \mathrm{g} / \mathrm{dL}$. The HS-Omega-3 Index by OmegaQuant (developed by True Health Diagnostics, Frisco, TX) was used to determine the red blood cell content of the following fatty acids: Omega-3 Total, Alpha-Linolenic Acid (ALA), Docosapentaenoic (DPA), Eicosapentaenoic (EPA), Docosahexaenoic (DHA), HSOmega-3 Index (RBC EPA + DHA), Omega-6 Total, Arachidonic (AA), Linoleic (LA), Cis-Monounsaturated Total, Saturated Total, and Trans-Fat Index. SpectraCell ${ }^{\circ}$ Laboratories (Houston, TX; www.spectracell.com) testing was ascertained to gauge further insight with respect to nutrient factors affecting the RBC omega-3 results [41]. 


\section{Genetics}

A subgroup of participants $(n=99)$ were buccal cheekswabbed, segregated into 5 risk categories and categorized for total risk \& lifetime risk using a 5 genotype $\mathrm{CFH}, \mathrm{C} 3$, ARMS2 \& MT-ND2 8 SNP DNA array (www.njlabs.com) [42]. We also evaluated the SNP (single nucleotide polymorphisms) methylenetetrahydrofolate reductase (MTHF R) C677T and A1298C for folic acid, because of their potential synergistic relationship to DHA status [43].

\section{Statistics}

All statistical analyses were performed in SPSS version 25.0 for Windows (SPSS, Inc., Chicago, IL). Independent Student's $t$-tests analyzed the differences between the MPOD spatial profile groups (with and without foveal dip) and those with or without measurable carotenoids in the serum, whereas an ANCOVA was used to correct for age where appropriate. Kolmogorov-Smirnov tests revealed a significant deviation from a normal distribution for all variables except age, \% body fat, MPOD, cRT, contrast (not contact) sensitivity, DHA, Omega-3 index, skin carotenoids, zinc, homocysteine, HDL cholesterol, HDL
$2 \mathrm{~b}$ and COQ10. The Pearson $\mathrm{X}^{2}$ test and Mann-Whitney $U$ test assessed any difference between categories and groups that showed an abnormal distribution. Preliminary analysis ensured no violation of assumptions of normality, or high correlation between the independent variables. Binomial logistic regression ascertained the effects of MPOD peak and volume, EPA, DHA, and Omega-3 index against FMPD presence. We also applied the binomial logistic regression analysis to further ascertain the effects of Holman Omega-3 Index modifiers: COQ10, anti-inflammatory Spectracell ${ }^{\oplus}$ (Houston, TX) serum calcitriol 1, $25 \mathrm{OH}$ Vitamin D3 white blood cell (WBC) activity, total high-density lipoprotein (HDL), HDL 2b, hs-CRP, and LP(a) against FMPD presence. Statistical significance was accepted at the $95 \%$ confidence level $(P<0.05)$.

\section{Results}

Demographic, genetic, macular, and skin carotenoid pigmentation

Table 1 displays characteristics of the offspring of AMD patients with and without a FMPD. Population peak MPOD significantly decreased with age (Spearman's rho

Table 1 EBAMD Subject characteristics: FMPD (Foveal Macular Pigment Dip) versus No Dip (corrected for age). Mean \pm SD data is presented unless otherwise stated. Statistical significance is presented in bold

\begin{tabular}{|c|c|c|c|c|}
\hline Variable & Total & $\begin{array}{l}\text { MPOD spatial profile: } \\
\text { FMPD }\end{array}$ & $\begin{array}{l}\text { MPOD spatial profile: } \\
\text { No Dip }\end{array}$ & $\mathbf{P}$ \\
\hline Offspring subjects (\%) & $130(100 \%)$ & $53(41 \%)$ & 77 (59\%) & \\
\hline Age (years) & $62.8 \pm 8.6$ & $60.6 \pm 8.0$ & $64.4 \pm 8.7$ & 0.012 \\
\hline Gender & 36 (28\%): & 11 (21\%): & 25 (32\%): & 0.14 \\
\hline Male: Female (\%) & $94(72 \%)$ & $42(79 \%)$ & $52(68 \%)$ & \\
\hline \% Body Fat (bioelectric impedance) & $32.6 \pm 7.8$ & $32.6 \pm 7.7$ & $32.5 \pm 8.0$ & 0.92 \\
\hline Body Mass Index $\left(\mathrm{kg} / \mathrm{m}^{2}\right)$ & $25.4 \pm 4.8$ & $25.4 \pm 5.3$ & $25.5 \pm 4.5$ & 0.49 \\
\hline ARIS MP Peak (du) & $0.80 \pm 0.21$ & $0.85 \pm 0.20$ & $0.77 \pm 0.21$ & 0.39 \\
\hline ARIS MP Volume & $3963 \pm 1222$ & $4310 \pm 1156$ & $3723 \pm 1217$ & 0.10 \\
\hline Central retinal thickness $(\mu \mathrm{m})(n=72)$ & $238 \pm 21.0$ & $232 \pm 17.8$ & $243 \pm 22.2$ & 0.010 \\
\hline Visual acuity (converted to decimals) & $0.92 \pm 0.22$ & $0.91 \pm 0.22$ & $0.93 \pm 0.21$ & 0.61 \\
\hline Contrast sensitivity (AUC) & $362 \pm 109$ & $362 \pm 104$ & $361 \pm 114$ & 0.94 \\
\hline DHA (\%) & $4.94 \pm 1.42$ & $4.62 \pm 1.36$ & $5.15 \pm 1.42$ & 0.040 \\
\hline EPA (\%) & $1.07 \pm 0.68$ & $0.92 \pm 0.559$ & $1.16 \pm 0.744$ & 0.10 \\
\hline HS-n3 index (\%) & $6.03 \pm 1.99$ & $5.55 \pm 1.80$ & $6.34 \pm 2.05$ & 0.029 \\
\hline Serum $L(\mu g / d L)$ & $24.8 \pm 15.7$ & $23.7 \pm 13.1$ & $25.6 \pm 17.3$ & 0.98 \\
\hline Serum Z $(\mu \mathrm{g} / \mathrm{dL})$ & $6.89 \pm 6.12$ & $6.34 \pm 5.41$ & $7.28 \pm 6.59$ & 0.34 \\
\hline L: Z ratio & $4.45 \pm 1.84$ & $4.75 \pm 2.20$ & $4.24 \pm 1.52$ & 0.31 \\
\hline Skin carotenoids & $34,525 \pm 13,970$ & $33,528 \pm 14,331$ & $35,225 \pm 13,766$ & 0.50 \\
\hline
\end{tabular}

Folic acid mutations

Negative: Heterozygous: Homozygous

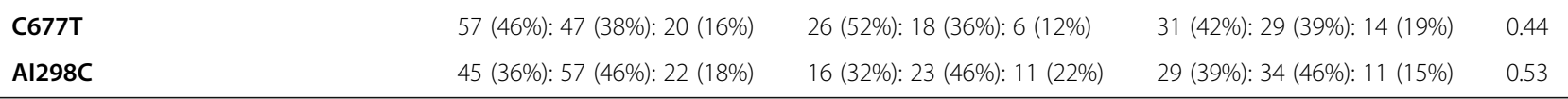

Du Density units, AUC Area under the curve, MPOD Macular pigment optical density, FMPD Foveal macular pigment dip, MP Macular pigment, DHA Docosahexaenoic acid, EPA Eicosapentaenoic acid, Serum L Serum Lutein, Serum Z Serum Zeaxanthin 
$\left.\mathrm{r}_{\mathrm{s}}(128)=-0.519, P<0.0001\right)$ as did MPOD volume (Spearman's rho $\left.r_{\mathrm{s}}(127)=-0.524, P<0.0001\right)$, indicating $27 \%$ of the variance in both parameters was explained by age. There was no significant relationship between central 1-degree foveal MP and the MP distribution integrated area, using either specular reflectance or QuantifEye ${ }^{\oplus}$ heterochromic flicker photometry.

FMPD was common in AMD offspring as $n=53(41 \%$ of offspring) presented this phenomenon. $62 \%(n=20)$ displayed the phenomenon in one eye and $38 \%(n=33)$ displayed a foveal dip in both retinas, with no gender, BMI or \%-age body fat effect. Paradoxically, younger age was significantly associated with an FMPD central dip $(P=0.012)$, and FMPD offspring also had denser average bi-retinal peak MPOD $(0.85 \pm 0.20 \mathrm{du})$, compared with those without FMPD $(0.77 \pm 0.21 \mathrm{du})$. This difference, however, was not significant after correction for age ( $F$ $\left.(1,125)=0.757, P=0.39, \eta_{\mathrm{p}}{ }^{2}=0.006\right)$. FMPD offspring also had denser average bi-retinal MPOD volume $(4310 \pm 1156 \mathrm{du})$ compared to those without FMPD (3723 $\pm 1217 \mathrm{du}$ ), however once again corrected for age, this seemingly compensatory increase in non-foveal retinal pigmentation was non-significant $(\mathrm{F}(1,124)=2.84$, $P=0.095, \eta_{\mathrm{p}}{ }^{2}=0.022$ ).

A comprehensive ophthalmological evaluation was completed on all patients by the same examiner (SGP) revealing no clinically significant drusen or retinal pigment epithelium changes. All patients had a best corrected vision of $20 / 25$ or better in both eyes. SD-OCT structural data was determined on a population subset $(n=72)$. After correcting for age, central retinal thickness at the fovea (cRT) was thinner where FMPD was observed $(232 \pm 17.8 \mu \mathrm{m})$, versus without a MPOD dip $(243 \pm 22.2 \mu \mathrm{m} ; \mathrm{F}(1,69)=7.09, P=0.01)$. Neither visual acuity nor contrast sensitivity discriminated between the two offspring groups $(n=130, P=0.61$ and $P=0.94$; Table 1).

Population skin carotenoids scores, a surrogate measure of systemic carotenoids, were $34,525 \pm 13,970$ with no correlation to age (Pearson $r=0.12 ; P=0.18$ ). Skin carotenoids were lower in those with a FMPD (33,528 \pm 14,331 units) versus those without $(35,225 \pm 13,766$ units $)$ but not statistically significant $(P=0.50)$. Serum $\mathrm{L}, \mathrm{Z}$ and the $\mathrm{L}: \mathrm{Z}$ ratio are shown in Table 1 . Although not significant, serum $\mathrm{L}$ and $\mathrm{Z}$ were both decreased and the $\mathrm{L}: \mathrm{Z}$ ratio was increased when a FMPD was present, compared to those without a central dip $(P=0.31)$.

A Chi-square test for independence was performed to investigate the relationship between FMPD and 5 prominent DNA risk categories. Risk categories 1 and 2 to 4 were compared to prevent violation of the frequency assumption (count $>10$ ), as categories 3 and 5 were infrequent. The proportion of participants showing an FMPD and higher risk genetic scores did not significantly differ from those without a dip $\left[\chi^{2}(1)=0.029, \quad P=0.87\right]$. MTHFR SNPs C677T and A1298C showed no significant difference in those presenting with FMPD compared to controls $(P=0.44$ and $P=0.53$, respectively) (Table 1).

\section{Omega-3 index, DHA, and EPA}

The RBC omega-3 fatty acid status was different in FMPD offspring versus those without a central dip (Table 1). RBC content of docosahexaenoic acid (DHA) was reduced in FMPD offspring vs. controls [4.62\% (1.36\%) vs. $5.15 \%$ (1.42\%); $P=0.04]$. RBC Eicosapentaenoic acid (EPA) also trended lower in FMPD subjects vs. controls $[0.92 \%(0.56 \%)$ vs. $1.16 \%(0.74 \%) ; P=0.10]$, although not significantly. However, the Omega-3 Index (RBC EPA + DHA) was significantly decreased in FMPD offspring [5.55\% (1.80\%) vs. $6.34 \%$ (2.05\%); $P=0.03$ ].

\section{Predictors of MPOD foveal dip status}

A binomial logistic regression was performed to ascertain the effects of MPOD peak and volume, EPA, DHA, Omega-3 index on the likelihood of offspring having a FMPD. The logistic regression model was statistically significant $[X 2(5)=11.81, P=0.038]$. The model explained $12.8 \%$ (Nagelkerke $\mathrm{R}^{2}$ ) of the variance in FMPD and correctly classified $68 \%$ of cases. Specificity of our model was $86 \%$ with a positive predictive value of $67 \%$. We applied the binomial regression analysis to further ascertain the effects of Holman Omega-3 index modifiers: CoQ10, anti-inflammatory Spectracell ${ }^{\circledR}$ (Houston, TX) serum calcitriol 1, $25 \mathrm{OH}$ Vitamin D3 white blood cell (WBC) activity, Total High-density lipoprotein (HDL), HDL 2b, hs-CRP, and LP(a) on the likelihood that participants presented with a FMPD. The logistic regression model was highly suggestive, but not statistically significant $\left[\chi^{2(6)}=11.952, P=0.063\right]$.

\section{Serum zeaxanthin}

$40 \%$ of subjects presented with low serum Z levels (< $2.9 \mu \mathrm{g} / \mathrm{dL}$ ). FMPD offspring exhibiting low serum $\mathrm{Z}$ (44\%) did not statistically differ compared to controls (37\%; $P=0.49$ ). We further investigated the effect of low serum $\mathrm{Z}$ on all our serum nutritional biomarkers because of zeaxanthin's central foveola location. Independent t-tests and Mann-Whitney $U$ test results are shown in Table 2. Those subjects with low serum $\mathrm{Z}$ showed significantly higher contrast sensitivity $(P=0.049)$, but significantly decreased RBC DHA $(P=0.00034)$ and EPA $(P=0.041)$, decreased RBC Omega $3(P=0.0025)$, decreased RBC Omega-3 index $(P=0.0011)$, increased Spectracell (1,25 hydroxy-vitamin D) calcitriol antiinflammatory activity $(P=0.037)$, fewer HDL $2 \mathrm{~b}$ molecules $(P=0.018)$ and increased Chromium $(P=0.014)$ 
Table 2 Independent t-test and non-parametric Mann-Whitney ${ }^{\dagger}$ test analyses of differences in nutritional biomarkers for those presenting low $(<2.9 \mu \mathrm{g} / \mathrm{dL})$ versus high $(\geq 2.9 \mu \mathrm{g} / \mathrm{dL})$ serum zeaxanthin. Mean \pm SD data is presented. Statistical significance is presented in bold

\begin{tabular}{|c|c|c|c|}
\hline Variable & Serum $Z(<2.9 \mu \mathrm{g} / \mathrm{dL})$ & Serum $Z(\geq 2.9 \mu \mathrm{g} / \mathrm{dL})$ & $\mathbf{P}$ \\
\hline Offspring subjects (\%) & $50(40 \%)$ & $76(60 \%)$ & \\
\hline Age (years) & $61.4 \pm 9.1$ & $63.7 \pm 8.3$ & 0.15 \\
\hline$\%$ Body Fat measurement & $33.0 \pm 8.5$ & $32.2 \pm 7.5$ & 0.62 \\
\hline Body Mass Index $\left(\mathrm{kg} / \mathrm{m}^{2}\right)$ & $26.5 \pm 5.8$ & $24.7 \pm 4.1$ & $0.11^{\dagger}$ \\
\hline ARIS MP Peak (du) & $0.80 \pm 0.22$ & $0.81 \pm 0.20$ & 0.95 \\
\hline ARIS MP Volume & $3949 \pm 1310$ & $4005 \pm 1162$ & 0.81 \\
\hline Central retinal thickness $(\mu \mathrm{m})(n=68)$ & $239 \pm 22$ & $237 \pm 19$ & 0.82 \\
\hline Visual acuity (decimals) & $0.91 \pm 0.22$ & $0.92 \pm 0.22$ & $0.77^{\dagger}$ \\
\hline Contrast sensitivity $(A \cup C)$ & $383 \pm 100$ & $344 \pm 113$ & 0.049 \\
\hline DHA (\%) & $4.36 \pm 1.35$ & $5.31 \pm 1.37$ & 0.00034 \\
\hline EPA (\%) & $0.92 \pm 0.58$ & $1.17 \pm 0.74$ & $0.041^{\dagger}$ \\
\hline HS-n3 index & $5.30 \pm 1.84$ & $6.52 \pm 1.99$ & 0.0011 \\
\hline Skin carotenoids & $33,132 \pm 12,334$ & $35,763 \pm 14,896$ & 0.31 \\
\hline Homocysteine ( $\mu \mathrm{mol} / \mathrm{L})$ & $9.7 \pm 2.6$ & $9.9 \pm 2.5$ & 0.71 \\
\hline Zinc & $40.7 \pm 6.7$ & $41.8 \pm 5.1$ & 0.303 \\
\hline Copper & $52.0 \pm 5.3$ & $52.0 \pm 5.3$ & $0.91^{\dagger}$ \\
\hline \multicolumn{4}{|l|}{ Vitamin } \\
\hline B1 & $91.2 \pm 8.2$ & $92.6 \pm 7.9$ & $0.39^{\dagger}$ \\
\hline B3 & $92.0 \pm 6.1$ & $92.4 \pm 6.9$ & $0.72^{\dagger}$ \\
\hline B6 & $63.0 \pm 7.2$ & $65.5 \pm 5.6$ & $0.079^{\dagger}$ \\
\hline B9 (folate) & $40.54 \pm 5.1$ & $41.45 \pm 6.2$ & $0.19^{\dagger}$ \\
\hline B12 & $18.8 \pm 3.9$ & $18.6 \pm 4.5$ & $0.87^{\dagger}$ \\
\hline D3 (1,25 WBC Calcitriol Activity) & $64.9 \pm 10.8$ & $61.878 \pm 8.9$ & $0.037^{\dagger}$ \\
\hline Omega 3 & $8.1 \pm 2.2$ & $9.5 \pm 2.4$ & $0.0025^{+}$ \\
\hline Insulin $(\mu \mid \mathrm{U} / \mathrm{mL})$ & $46.9 \pm 8.2$ & $46.6 \pm 8.0$ & $0.81^{\dagger}$ \\
\hline Chromium & $46.8 \pm 4.7$ & $44.8 \pm 5.1$ & $0.014^{\dagger}$ \\
\hline HDL cholesterol (nmol/L) & $64.3 \pm 15.3$ & $70.8 \pm 19.5$ & 0.0556 \\
\hline Total HDL Particles (nmol/L) & $8674 \pm 1016$ & $8379 \pm 1408$ & $0.099^{\dagger}$ \\
\hline HDL $\mathbf{2 b}(\mathrm{nmol} / \mathrm{L})$ & $2393 \pm 642$ & $2701 \pm 714$ & 0.0182 \\
\hline hs-CRP (mg/L) & $1.78 \pm 2.11$ & $2.05 \pm 2.74$ & $0.64^{\dagger}$ \\
\hline COQ10 & $91.2 \pm 4.23$ & $90.9 \pm 4.15$ & 0.71 \\
\hline $\mathrm{LP}(\mathrm{a})(\mathrm{mg} / \mathrm{dL})$ & $19.9 \pm 24.1$ & $30.2 \pm 41.6$ & $0.34^{\dagger}$ \\
\hline
\end{tabular}

Serum Z Serum Zeaxanthin, MP Macular Pigment, DHA Docosahexaenoic acid, EPA Eicosapentaenoic acid, HDL High-density lipoprotein, $h s$-CRP High Sensitivity CReactive Protein, LP Lipoprotein

${ }^{+}$signifies that a Man-Whitney test was used to obtain the corresponding p-value

compared to subjects whose serum zeaxanthin was $\geq 2.9 \mu \mathrm{g} / \mathrm{dL}$.

\section{Discussion}

EBAMD is a preventative medicine analysis of genetic, nutritional and subclinical risk factors for developing AMD, given a parental AMD history [32]. MPOD dip prevalence in at least one eye of the offspring of AMD parent(s) was surprisingly high at $41 \%$, double that reported within the general Caucasian population $[23,25$,
32]. This was unexpected since our population already excluded offspring more likely to have atypical profiles (i.e. foveal macula pigment dip) such as non-Caucasians with larger concentrations of skin pigments $[25,44,45]$ smokers [17] and diseased retinas (AMD patients) [22]. Consistent with the MPOD literature [10, 46, 47], we found significantly decreased MPOD with age. AMD genetic risk test failed to reflect a difference, suggesting that additional SNPs, multiple systemic alleles or environmental epigenetic modulators might be at work. It 
was surprising that FMPDs were more often unilateral suggesting the possibility of sampling variation or measurement error. Commonly, right and left retinas are more symmetrical in MPOD levels and spatial profiles $[48,49]$. However, such asymmetry has been found in older population [50], history of central serous chorioretinopathy [51], and Starghardt's disease [52].

EBAMD results agree with null genetic results from a similarly aged cohort evaluating SD-OCT retinal structure in pre-clinical AMD, against 17 SNP biomarkers [53]. The authors stated, "No consistent changes were observed in retinal structure at multiple locations that are associated with pre-clinical AMD, based on AMD genetic risk or with aging" [53], although neither macular pigment nor its foveal architecture were evaluated in this study.

In EBAMD, offspring of an AMD parent(s) presenting with a FMPD showed significantly reduced RBC serum concentrations of DHA compared to those without an FMPD. This was independent of other known FMPD risk factors in multivariate analysis, as well as general population risk factors. This seminal finding suggests that a low DHA concentration may play an ageindependent role in the pathophysiology and hence vulnerability for AMD, in the offspring of an AMD parent(s). Indeed, offspring with FMPD were some 4 years younger, in agreement with authors who have found an increase in the RBC Omega-3 Index with age [54]. Our results reveal that offspring of an AMD parent(s), without any visible clinical signs of AMD, show an average yet insufficient Omega-3 Index [55]. It is possible that higher DHA may be required for the eye to mitigate retinal FMPD.

Although not statistically significant, FMPDs were associated with a higher L:Z ratio. It is known that in combination with the macular distribution of the 2 dietary xanthophylls (foveal zeaxanthin and parafoveal lutein), increased plasma zeaxanthin is significantly associated with reduced risk of AMD [56]. Indeed, it has been recently demonstrated that high dose $(8 \mathrm{mg})$ zeaxanthin supplementation augments ('normalizes') both central MPOD and foveal visual scotomas in subjects presenting with atypical FMPD spatial profiles [40, 57, 58]. However, similar to Zeimer et al. [59], our data also suggests that the increased L:Z ratio does not create the FMPD but potentially amplifies it, which supports the hypothesis that lower serum Z (or higher L:Z ratio) only partially explains the presence of FMPD.

FMPD offspring exhibiting low $(<2.9 \mu \mathrm{g} / \mathrm{dL})$ serum $\mathrm{Z}$ did not statistically differ compared to controls, however offspring of AMD patients presenting with low serum Z levels $(\sim 40 \%)$ had a significantly lower omega-3 index and significantly lower levels of DHA and HDL $2 \mathrm{~b}$. This suggests an important interaction between omega-3 fatty acids, lipoproteins and carotenoids such as zeaxanthin.
It has been shown that DHA increases macular pigment in the central region, where zeaxanthin is the most prominent [60]. Furthermore, in a randomized, controlled trial, Johnson et al. [60] found that DHA facilitated accumulation of the carotenoid lutein in the blood and the macula, and that some of these effects may be due to alterations in lipoprotein profile by DHA. More work should be completed to study the possible interaction between omega- 3 fatty acids, carotenoids and lipoproteins.

EBAMD also finds significant association between MPOD spatial profiles and central retinal thickness with individuals presenting with FMPD having thinner foveas. In Caucasians, a thicker central retina has been associated with significantly higher MPOD levels [61, 62], however, this was not evident from other reports [20, 21]. Studies have shown a significantly thinner central retina and wider foveas of healthy non-white patients compared to Caucasians [63-65]. Similar to heightened central dip prevalence, thinner retinas appear more comparable to ethnic populations that are known for increased prevalence of AMD [44, 45]. The relationship between the central- dip and AMD is still unclear because the mechanism of the formation of the central-dip is unclear. Mueller cells at the fovea contain macular pigment, and in many cases, the central dip is produced by the damage to Mueller cell cones induced by vitreous traction [66-68]. Furthermore, it is unknown whether the damage in Mueller cells, and not diminished pigment, becomes the risk factor for AMD development. The theme must be investigated further.

\section{EBAMD design, strengths, and limitations}

A major limitation of this study is the lack of a control group of children who do not have a parent with AMD, as well as reliance on previous publications in which different instruments were used to measure macular pigment [19-22]. The issue of standardization using a newly introduced metric called MPOV (Macular Pigment Optical Volume), obtained by dual - wavelength autofluorescence, should be a major advance in confirming our results [69].

The utility of spectral reflectance to measure and visualize the foveal dip has been questioned and debated, especially in older patients [70]. Specifically, the major disadvantage of single-wave fundus reflectometry MPOD determination is the requirement for normal lens and retinal architecture [71]. Therefore, results may be unreliable in patients with advanced AMD or advanced cataracts. However, offspring with AMD and advanced cataract were excluded in EBAMD, rendering this limitation irrelevant or merely inconsequential.

There is a remote possibility that apparent MPOD foveal dips reflect differential absorption by other features 
of the lens or ocular media and the method used to assess MPOD (single wavelength autoflourescence) may not adequately correct for such features. However, again the patients in this study were relatively young, mitigating the confounding effects of lenticular or vitreoretinal pathology. Secondly, our 3D determination of a central MPOD dip in younger healthy offspring considered the relative change between the center and 2 degrees eccentricity, and the coefficient of repeatability was calculated in order to account for specular reflectance measurement variability.

Unlike heterochromatic flicker photometry (HFP), fundus reflectometry is an objective method of measurement and therefore may obtain MPOD estimates in special needs populations [37]. It has also proven to be repeatable and estimates of MPOD can be obtained in short duration [37, 38, 72]. Other strengths include objective assessment of carotenoid and fatty acid biomarkers instead of dietary questionnaires, and relatively equally sized cohorts.

\section{Conclusions}

AMD offspring demonstrated non-protective macular pigment topography, often low $(<2.9 \mu \mathrm{g} / \mathrm{dL})$ zeaxanthin, and significantly thinner foveas. Among all EBAMD factors and disease markers analyzed, \% RBC membrane DHA was the magnanimous factor significant among $41 \%$ of AMD offspring with FMPD. EBAMD omega-3 $\mathrm{RBC}$ index data, a measure of long term essential fatty acid status, supports the importance of 'essential fatty' acids in AMD, and our contention that DHA is the predominant essential fatty acid.

Given the global AMD epidemic, Scripps EBAMD data are of clinical interest since participants were all AMD offspring lacking three of the major predisposing factors attributable to the MPOD foveal dip phenomenon: advanced age, smoking and an AMD clinical diagnosis. EBAMD data argues for further use of research and clinical instrumentation to measure MPOD distribution in AMD offspring, instead of peak MPOD screening, by the traditional but nonetheless entirely subjective HFP measure.

\section{Abbreviations \\ AMD: Age-related macular degeneration; MP: Macular Pigment; RBC: Red blood cell; PUFA: Polyunsaturated fatty acid; MPOD: Macular pigment optical density; FMPD: Foveal macular pigment dip; DHA: Docosahexaenoic acid; EPA: Eicosapentaenoic acid; ALA: Alpha Lipoic Acid; DPA: Docosapentaenoic acid; cRT: Central retinal thickness; MTHFR: Methylenetetrahydrofolate reductase}

\section{Acknowledgements}

We acknowledge the critical review of this manuscript by Bill Harris, Ph.D. We thank Jennifer Rood, Ph.D. at Pennington Biomedical Research Center and Anne Hanneken, M. D at Scripps Health for help with the completion of this study.

\section{Authors' contributions}

GAR, SPR, CBP and SGP designed the research plan; GAR, GP and SGP conducted research; GAR, SPR, BH and CP analyzed data; GAR, SPR, BH, CP and SGP wrote the paper; SGP had primary responsibility for final content. All the authors read and approved the final manuscript.

\section{Authors' information}

Grant Allen Rutledge is currently a Postdoctoral Researcher at the Jean Mayer USDA Human Nutrition Research Center on Aging (HNRCA) at Tufts University.

\section{Funding}

The Scripps Health System - IRB-11-5677, Fonseca estate grant 14110001579 awarded in 2007 and 2012 for a total of $\$ 315,000$. The remainder of the money used to finish this study was raised through the Scripps Foundation via a fund-raising event. The funding source did not have any role in the design of the study, collection, analysis and interpretation of the data, and in writing of the manuscript.

\section{Availability of data and materials}

Data described in the manuscript will be made available by the corresponding author (GAR) upon request.

\section{Ethics approval and consent to participate}

The 5-year study commenced on 01/01/2012 following Scripps Health IRB approval (11-5677) registration. Written informed consent following the tenets of the Declaration of Helsinki was obtained from all study participants.

\section{Consent for publication}

Not Applicable.

\section{Competing interests}

The authors declare that they have no competing interests.

\section{Author details}

${ }^{1}$ Scripps Health/Scripps Memorial Hospital/Scripps Mericos Eye Institute Scripps Clinical Research Service, La Jolla, CA, USA. ${ }^{2}$ Department of Ecology and Evolutionary Biology, University of California, Irvine, CA, USA. ${ }^{3}$ USDA Human Nutrition Research Center on Aging, Boston, MA, USA. ${ }^{4}$ Eye Clinics, Captain James A. Lovell Federal Health Care Center, North Chicago, IL, USA. ${ }^{5}$ Centre for Applied Vision Research, Division of Optometry and Vision Sciences, City, University of London, London, UK.

Received: 22 May 2020 Accepted: 23 November 2020

Published online: 02 December 2020

\section{References}

1. Lim LS, Mitchell P, Seddon JM, Holz FG, Wong TY. Age-related macular degeneration. Lancet. 2012;379:1728-38.

2. Congdon N, O'Colmain B, Klaver CC, Klein R, Munoz B, Friedman DS, Kempen J, Taylor HR, Mitchell P. Causes and prevalence of visual impairment among adults in the United States. Arch Ophthalmol. 2004; 122(4):477-85.

3. Spaide RF, Armstrong D, Browne R. Continuing medical education review: Choroidal neovascularization in age-related macular degeneration-what is the cause? Retina. 2003;23(5):1081-3.

4. Klaver CC, Wolfs RC, Assink JJ, van Duijn CM, Hofman A, de Jong PT Genetic risk of age-related maculopathy. Population-based familial aggregation study. Arch Opthalmol. 1998:116(12):1646-51.

5. Smith W, Mitchell P. Family history and age-related maculopathy. The blue mountains eye study. Aust N Z J Ophthalmol. 1998;26(3):203-6.

6. Klein ML, Mauldin WM, Stoumbos VD. Heredity and age-related macular degeneration. Observations in monozygotic twins. Arch Ophthalmol. 1994; 112(7):932-7.

7. Heiba IM, Elston RC, Klein BE, Klein R. Sibling correlations and segregation analysis of age-related maculopathy: the beaver dam eye study. Genet Epidemiol. 1994;11(1):51-67.

8. Meyers SM, Greene T, Gutman FA. A twin study of age-related macular degeneration. Am J Ophthalmol. 1995;120(6):757-66.

9. Bone RA, Landrum JT, Hime GW, Cains A, Zamor J. Stereochemistry of the human macular carotenoids. Invest Ophthalmol Vis Sci. 1993;34:2033-40. 
10. Beatty S, Murray IJ, Henson DB, Carden D, Koh H, Boulton ME. Macular pigment and risk for age-related macular degeneration in subjects from a northern European population. Invest Ophthalmol Vis Sci. 2001;42(2):439-46.

11. Nolan JM, Stack J, O'Donovan O, Loane E, Beatty S. Risk factors for agerelated maculopathy are associated with a relative lack of macular pigment. Exp Eye Res. 2007:84(1):61-74.

12. Hammond BR, Curran-Celentano J, Judd S, Fuld K, Krinsky NI, Wooten BR, Snodderly DM. Sex differences in macular pigment optical density: relation to plasma carotenoid concentrations and dietary patterns. Vis Res. 1996;36: 2001-12.

13. Ciulla TA, Curran-Celantano J, Cooper DA, Hammond BR, Danis RP, Pratt LM, Riccardi KA, Filloon TG. Macular pigment optical density in a midwestern sample. Ophthalmol. 2001;108:730-7.

14. Mares JA, LaRowe TL, Snodderly DM, Moeller SM, Gruber MJ, Klein ML, Wooten BR, Johnson EJ, Chappell RJ. Predictors of optical density of lutein and zeaxanthin in retinas of older women in the carotenoids in age-related eye disease study, an ancillary study of the Women's Health Initiative. Am J Clin Nutr. 2006:84:1107-22.

15. Arunkumar R, Calvo CM, Conrady CD, Bernstein PS. Review what do we know about the macular pigment in AMD: the past, the present, and the future. The Royal College of Ophthalmologists. 2018 May;32(5):992-1004. https://doi.org/10.1038/s41433-018-0044-0.

16. Pratt S, Richer S, Perry CB, Rutledge G, Podella C. Early biomarkers of AMD (EBAMD) study - design and baseline data: IRB-11-5677. Invest Ophthalmol Vis Sci. 2013;54(15):6189.

17. Snodderly DM, Auran JD, Delori FC. The macular pigment II. Spatial distribution in primate retinas. Invest Ophthalmol Vis Sci. 1984;25(6):674-85.

18. Bone RA, Landrum JT, Fernandez L, Tarsis SL. Analysis of the macular pigment by HPLC: retinal distribution and age study. Invest Ophthalmol Vis Sci. 1988;29(6):843-9.

19. Nolan JM, Stringham JM, Beatty S, Snodderly DM. Spatial profile of macular pigment and its relationship to foveal architecture. Invest Ophthalmol Vis Sci. 2008;49(5):2134-42.

20. Kirby ML, Galea M, Loane E, Stack J, Beatty S, Nolan JM. Foveal anatomic associations with the secondary peak and the slope of the macular pigment spatial profile. Invest Ophthalmol Vis Sci. 2009;50(3):1383-91.

21. Delori FC, Goger DG, Keilhauer C, Salvetti P, Staurenghi G. Bi-modal spatial distribution of macular pigment: evidence of a gender relationship. J Opt Soc Am. 2006;23(3):521-38

22. Dietzel M, Zeimer M, Heimes B, Pauleikhoff D, Hense HW. The ringlike structure of macular pigment in age-related maculopathy: results from the muenster aging and retina study (MARS). Invest Ophthalmol Vis Sci. 2011; 52(11):8016-24.

23. Berendschot TTJM, van Norren D. Macular pigment shows ringlike structures. Invest Ophthalmol Vis Sci. 2006:47(2):709-14.

24. Kirby ML, Beatty S, Loane E, Akkali MC, Connolly EE, Stack J, Nolan JM. A central dip in the macular pigment spatial profile is associated with age and smoking. Invest Ophthalmol Vis Sci. 2010;51(12):6722-8.

25. Huntjens B, Asaria TS, Dhanani S, Konstantakopoulou E, Ctori I. Macular pigment spatial profiles in south Asian and white subjects. Invest Ophthalmol Vis Sci. 2014;55(3):1440-6.

26. Connolly EE, Beatty S, Thurnham DI, Loughman J, Howard AN, Stack J, Nolan JM. Augmentation of macular pigment following supplementation with all three macular carotenoids: an exploratory study. Curr Eye Res. 2010; 35(4):335-51.

27. Jorgenson E, Melles RB, Hoffmann TJ, Jia X, Sakoda LC, Kvale MN, Banda Y, Schaefer C, Risch N, Shen L. Common coding variants in the HLA-DQB1 region confer susceptibility to age-related macular degeneration. Eur J Hum Genet. 2016;24(7):1049-55.

28. The Age-Related Eye Disease Study 2 (AREDS2) Research Group. Lutein + Zeaxanthin and omega-3 fatty acids for age-related macular degeneration: the age-related eye disease study 2 (AREDS2) randomized clinical trial. JAMA. 2013;309(19):2005-15.

29. SanGiovanni J, Chew EY, Agrón E, et al. The relationship of dietary $\omega$-3 longchain polyunsaturated fatty acid intake with incident age-related macular degeneration: AREDS report no. 23. Arch Ophthalmol. 2008;126(9):1274-9.

30. Augood C, Chakravarthy U, Young I, Vioque J, TVM de Jong P, Bentham G, Mati R, Seland J, Soubrane G, Tomazzoli L, Topouzis F, Vingerling JR, Fletcher AE. Oily fish consumption, dietary docosahexaenoic acid and eicosapentaenoic acid intakes, and associations with neovascular agerelated macular degeneration. Am J Clin Nutr. 2008;88(2):398-406.
31. Hodge WG, Barnes D, Schachter HM, Pan YI, Lowcock EC, Zhang L, Sampson M, Morrison A, Tran K, Miguelez M, Lewin G. Evidence for the effect of omega-3 fatty acids on progression of age-related macular degeneration: a systematic review. Retina. 2007;27(2):216-21.

32. Harris G, Pratt S, Richer SP. Age-Related Macular Degeneration. In: Kohlstadt I, editor. Food and nutrients in disease management. Boca Raton, FL: CRC Press: Taylor \& Francis Group; 2013. p. 1.

33. Bazan NG, Molina MF, Gordon WC. Docosahexaenoic acid signalolipidomics in nutrition: significance in aging, neuroinflammation, macular degeneration, Alzheimer's, and other neurodegenerative diseases. Annu Rev Nutr. 2011;31:321-51.

34. Ferris FL III, Wilkinson CP, Bird A, Chakravarthy U, Chew E, Csaky K, Sadda SR Clinical classification of age-related macular degeneration. Ophthalmology. 2013;120:844-51.

35. Van der Veen RL, Berendschot TT, Makridaki M, Hendrikse F, Carden D, Murray IJ. Correspondence between retinal reflectometry and a flicker-based technique in the measurement of macular pigment spatial profiles. J Biomed Opt. 2009;14(6):064046.

36. Richer SP, Stiles W, Graham-Hoffman K, Levin M, Ruskin D, Wrobel J, Park DW, Thomas C. Randomized, double-blind, placebo-controlled study of zeaxanthin and visual function in patients with atrophic age-related macular degeneration: the Zeaxanthin and visual function study (ZVF) FDA IND \#78, 973. Optometry. 2011;82(11):667-80.

37. Howells O, Eperjesi F, Bartlett H. Measuring macular pigment optical density in vivo: a review of techniques. Graefes Arch Clin Exp Ophthalmol. 2011; 249(3):315-47.

38. Berendschot $\Pi$, van Norren D. Objective determination of the macular pigment optical density using fundus reflectance spectroscopy. Arch Biochem Biophys. 2004;430(2):149-55

39. Conrady CD, Bell JP, Besch BM, Gorusupudi A, Farnsworth K, Ermakov I, Sharifzadeh M, Ermakova M, Gellermann W, Bernstein PS. Correlations between macular, skin, and serum carotenoids. Invest Ophthalmol Vis Sci. 2017;58(9):3616-27.

40. Richer SP, Stiles W, Statkute L, Pulido J, Frankowski J, Rudy D, Pei K, Tsipurski $\mathrm{M}$, Nyland J. A placebo-controlled, double blind, randomized trial of lutein and antioxidant supplementation for the treatment of age-related macular degeneration: the lutein antioxidant supplementation trial (LAST). Optometry. 2004;75:216-2130.

41. SpectraCell Laboratories. https://www.spectracell.com; 2018 Accessed 17.02.18.

42. Warwick A, Lotery A. Genetics and genetic testing for age-related macular degeneration. Eye (Lond). 2018;32(5):849-57.

43. Bhargava S, Tyagi SC. Nutriepigenetic regulation by folate-homocysteinemethionine axis: a review. Mol Cell Biochem. 2014;387(1-2):55-61.

44. Ctori I, Huntjens B. The association between foveal morphology and macular pigment spatial distribution: an ethnicity study. PloS One. 2017 12(1):e0169520.

45. Wolf-Schnurrbusch UEK, Röösli N, Weyermann E, Heldner MR, Höhne K, Wolf S. Ethnic differences in macular pigment density and distribution. Invest Ophthalmol Vis Sci. 2007:48(8):3783-7.

46. Berendschot TTJM, van Norren D. On the age dependency of the macular pigment optical density. Exp Eye Res. 2005;81(5):602-9.

47. Ciulla TA, Hammond BR. Macular pigment density and aging, assessed in the normal elderly and those with cataracts and age-related macular degeneration. Am J Ophthalmol. 2004;138(4):582-7.

48. Hammond BR, Wooten BR, Snodderly DM. Individual variations in the spatial profile of human macular pigment. J Opt Soc Am A Opt Image Sci Vis. 1997;14(6):1187-96.

49. Lam RF, Rao SK, Fan DS, Lau FT, Lam DS. Macular pigment optical density in a Chinese sample. Curr Eye Res. 2005;30(9):729-35.

50. Snodderly DM, Mares JA, Wooten BR, Oxton L, Gruber M, Ficek T. Macular pigment measurement by heterochromatic flicker photometry in older subjects: the carotenoids and age-related eye disease study. Invest Ophthalmol Vis Sci. 2004;45(2):531-8.

51. Putnam CM, Kinerk WT, Bassi CJ. Central serous chorioretinopathy produces macular pigment profile changes. Optom Vis Sci. 2013;90(7):e206-12.

52. Lambertus S, Bax NM, Groenewoud JMM, Cremers FPM, van der Wilt GJ, Klevering BJ, Theelen T, Hoyng CB. Asymmetric inter-eye progression in Stargardt disease. Invest Ophthalmol Vis Sci. 2016:57(15):6824-30.

53. Nusinowitz S, Wang Y, Kim P, Habib S, Baron R, Conley Y, Gorin M. Retinal structure in pre-clinical age-related macular degeneration. Curr Eye Res. 2017;43(3):376-82 
54. Harris WS, Pottala JV, Varvel SA, Borowski JJ, Ward JN, McConnell JP. Erythrocyte omega-3 fatty acids increase and linoleic acid decreases with age: observations from 160,000 patients. Prostaglandins Leukot Essent Fatty Acids. 2013;88(4):257-63.

55. Thuppal SV, von Schacky C, Harris WS, Sherif KD, Denby N, Steinbaum SR, Haycock B, Bailey RL. Discrepancy between knowledge and perceptions of dietary omega-3 fatty acid intake compared with the omega-3 index. Nutrients. 2017;9(9):E930.

56. Delcourt C, Carrière I, Delage M, Barberger-Gateau P, Schalch W, POLA Study Group. Plasma lutein and zeaxanthin and other carotenoids as modifiable risk factors for age-related maculopathy and cataract: the POLA study. Invest Ophthalmol Vis Sci. 2006;47(6):2329-35.

57. Richer SP, Cebold B, Katkar M, Huntjens B, Pratt SG. Restoration of central macular pigment dip with dietary RR Zeaxanthin supplementation in patients with AMD. Adv Ophthalmol Vis Syst. 2017;7(3):00219.

58. Nolan JM, Akkali MC, Loughman J, Howard AN, Beatty S. Macular carotenoid supplementation in subjects with atypical spatial profiles of macular pigment. Exp Eye Res. 2012;101:9-15.

59. Zeimer M, Dietzel M, Hense HW, Heimes B, Austermann U, Pauleikhoff D. Profiles of macular pigment optical density and their changes following supplemental lutein and zeaxanthin: new results from the LUNA study. Invest Ophthalmol Vis Sci. 2012:53:4852-9.

60. Johnson EJ, Chung HY, Caldarella SM, Snodderly DM. The influence of supplemental lutein and docosahexaenoic acid on serum, lipoproteins, and macular pigmentation. Am J Clin Nutr. 2008;87:1521-9.

61. Liew SM, Gilbert CE, Spector TD, Mellerio J, Van Kuijk FJ, Beatty S, Fitzke F, Marshall J, Hammond CJ. Central retinal thickness is positively correlated with macular pigment optical density. Exp Eye Res. 2006;82(5):915-20.

62. van der Veen RLP, Ostendorf S, Hendrikse F, Berendschot TTJM. Macular pigment optical density relates to foveal thickness. Eur J Ophthalmol. 2009; 19(5):836-41.

63. Kanis MJ, Berendschot TTJM, van Norren D. Interocular agreement in melanin and macular pigment optical density. Exp Eye Res. 2007:84(5):934-8.

64. Kashani AH, Zimmer-Galler IE, Shah SM, Dustin L, Do DV, Eliott D, Haller JA, Nguyen QD. Retinal thickness analysis by race, gender, and age using stratus OCT. Am J Ophthalmol. 2010;149(3):496-502.

65. Wagner-Schuman M, Dubis AM, Nordgren RN, Lei Y, Odell D, Chiao H, Weh E, Fischer W, Sulai Y, Dubra A, Carroll J. Race- and sex-related differences in retinal thickness and foveal pit morphology. Invest Ophthalmol Vis Sci. 2011; 52(1):625-34.

66. Obana A, Sasano H, Okazaki S, Otsuki Y, Seto T, Gohto Y. Evidence of carotenoid in surgically removed lamellar hole-associated Epiretinal proliferation. Invest Ophthalmol Vis Sci. 2017;58:5157-63.

67. Obana A, Gohto Y, Sasano H, et al. Spatial distribution of macular pigment estimated by autofluorescence imaging in elderly Japanese individuals. Jpn J Ophthalmol. 2020;64(2):160-70.

68. Obana A, Nakazawa R, Noma S, Sasano H, Gohto Y. Macular pigment in eyes with macular hole formation and its change after surgery. Transl Vis Sci Technol. 2020;9(11):28.

69. Green-Gomez M, Bernstein PS, Curcio CA, Moran R, Roche W, Nolan JM. Standardizing the assessment of macular pigment using a dual-wavelength autofluorescence technique. TransI Vis Sci \& Tech. 2019;8(6):41.

70. Dennison JL, Stack J, Beatty S, Nolan JM. Concordance of macular pigment measurements obtained using customized heterochromatic flicker photometry, dual-wavelength auto-fluorescence, and single-wavelength reflectance. Exp Eye Res. 2013;116:190-8.

71. Komar B, Rauscher FG, Wiedemann R, Dawczynski J. Macular pigment optical density measurements by one-wavelength reflection photometryinfluence of cataract surgery on the measurement results. Graefes Arch Clin Exp Ophthalmol. 2014;252(11):1717-27.

72. Davey PG, Ngo A, Cross J, Gierhart DL. Macular pigment reflectometry: development and evaluation of a novel clinical device for rapid objective assessment of the macular carotenoids: SPIE; 2019.

\section{Publisher's Note}

Springer Nature remains neutral with regard to jurisdictional claims in published maps and institutional affiliations.

Ready to submit your research? Choose BMC and benefit from:

- fast, convenient online submission

- thorough peer review by experienced researchers in your field

- rapid publication on acceptance

- support for research data, including large and complex data types

- gold Open Access which fosters wider collaboration and increased citations

- maximum visibility for your research: over $100 \mathrm{M}$ website views per year

At BMC, research is always in progress.

Learn more biomedcentral.com/submissions 